\title{
DEVELOPMENT AND IMPLEMENTATION OF A BIOINFORMATICS ONLINE DISTANCE EDUCATION LEARNING TOOL IN AFRICA
}

\author{
Oluwagbemi Olugbenga OLUSEUN \\ Department of Computer and Information Sciences \\ (Bioinformatics Unit) \\ College of Science and Technology \\ Covenant University, NIGERIA

\section{ABSTRACT}

New scientific research fields are evolving on a yearly basis but some parts of the African continent are less aware. Thus, there arises the need for a suitable implementation strategy in introducing the basic components of an emerging scientific field to some part of the African populace through the development of an online distance education learning tool. This emerging field is known as bioinformatics. This research work was instrumental in elucidating the need for a suitable implementation platform for bioinformatics education in parts of the African continent that are less aware of this innovative and interesting field. The aim of this research work was to disseminate the basic knowledge and applications of bioinformatics to these parts of the African continent.

Keywords: Bioinformatics; online distance learning tool; biotechnology; education.

\section{INTRODUCTION}

Computational Biology and Bioinformatics are terms for an interdisciplinary field joining information technology and biology that has skyrocketed in recent years. The field is located at the interface between the two scientific and technological disciplines that can be argued to drive a significant if not the dominating part of contemporary innovation (Thomas Lengauer, 2000).

Thus, Bioinformatics is an innovative field in the Sciences. However, some parts of the African continent have not been properly introduced and sensitized to this interesting bio-scientific and computing field; the awareness and impact of Bioinformatics education and its numerous benefits to the African economy have not been fully realized. The purpose of this research is to develop and implement an online distance learning web application tool for Bioinformatics distance education in the African continent with computing techniques. This research will be instrumental in educating about numerous applications and benefits of Bioinformatics to various sectors of the African economy. It will also serve as an important online distance learning tool in encouraging and providing useful insights to upcoming scientists in taking up different research interest and areas in Bioinformatics. 


\section{REVIEW OF RELEVANT LITERATURES}

Bioinformatics and computational biology involve the use or development of techniques including applied mathematics, informatics, statistics, computer science, artificial intelligence, chemistry, and biochemistry to solve biological problems usually on the molecular level. Bioinformatics more properly, refers to the creation and advancement of algorithms, computational and statistical techniques, and theory to solve formal and practical problems arising from the management and analysis of biological data [(Achuthsankar S Nair, 2007), (Aluru, Srinivas ,2006), and Baldi, P et al., (2001)]. Open learning is resource-based learning designed for individual use without the presence of a teacher. This learning can occur in campus and off-campus settings, and in full-time and part-time study.

Distance learning, however, refers to situations where the learner and teacher are geographically far apart. This could be relaying a lecture in one location to a number of other sites (DFID, 2008). Open and Distance Learning is often seen as the answer to expanding access to education and lifelong learning

In the technologically advanced world, the effectiveness of the internet and webbased distance learning has increased in concert with its increased popularity. It has been argued that, Internet based courses best serve "...independent and self confident students who do not feel that they are in serious need of intense interaction with tutors or lecturers when they go about their learning." (Y.J. Katz, 2002) Nevertheless, online courses are getting popular among other sections of the society too, such as homemakers, full time employees and busy parents who cannot afford to attend live classes. The Internet can offer the online learning process a variety of benefits, including "easy access to educational content, interaction, a cooperative learning process and the reuse of content." (H. Fuks, 2002) It is safe to say that, "distance learning, is an educational approach that integrates technology, connectivity, curricular content, and human resources."(J. Wilson, 2002). Bioinformatics distance learning will equally serve as an educational approach in informing and teaching some African countries that are less aware of its relevance and applications, the needed information that will enable the transformation of the educational and agricultural sectors of such countries.

\section{STATEMENT OF PROBLEM}

One of the major problems contending with some countries within the African continent is lack of proper awareness about new productive and innovative research fields. This problem has had its effects on mostly the agriculture and educational sector. Part of this problem can be solved by introducing online distance learning tools on innovative research fields like bioinformatics. Thus, the need for a suitable implementation strategy cannot be underestimated. Bioinformatics Online distance learning education tool is very essential with the following reasons:

Bioinformatics has been experiencing a very rapid growth since the past 3 years

$>$ There is serious shortage of manpower in this field

$>$ Bioinformatics is a rapidly evolving field (Lim Yun Ping, 2003). 
$>$ Many in some parts of Africa do not have the fundamental knowledge about bioinformatics.

> Many do not know the immense economic benefits that bioinformatics can offer.

$>$ Introducing a web application tool on bioinformatics online distance learning will help to adequately provide the fundamental knowledge required for college students which will help them prepare to pursue a good career in bioinformatics.

$>$ Few Universities in Africa offer bioinformatics as a discipline or engage in thorough and active research in bioinformatics. One of them is Covenant University in Nigeria and few other universities in South Africa.

$>$ Bioinformatics online distance education offers other benefits as well. It can effectively disseminate fundamental knowledge to those learners who have been denied access to classrooms. For example, women who are unable to attend traditional educational programs because of household responsibilities or cultural constraints provided they know how to read and have access to the internet.

\section{OBJECTIVES OF THE RESEARCH}

The objectives of the research are to develop a bioinformatics online distance learning application. This application will be useful in educating both students and parents about this innovative field and its various applications to the African economy, especially the education and agricultural sector.

\section{BENEFITS OF THIS RESEARCH}

One of the major benefits of the proposed bioinformatics online distance learning education tool is that it will be a freely functional tool without charging people school fees. Thus, it will provide basic information about bioinformatics and its applications for interested users free of charge.

Another very important benefit of this type of online distance educational tool is that, it will attract greater access. Distance education programs can increase educational access by reaching out to four commonly excluded groups.

These are secondary school graduates who are preparing to gain admission to the university, married women with household responsibilities, geographically isolated students, and economically disadvantaged communities(provided that they have Internet access facilities). Of these, the largest and most rapidly growing group is composed of secondary graduates who were successful in their secondary school certificate exams but unsuccessful in the competitive admission process for tertiary education. Low tertiary enrollment rates mean high levels of exclusion (William Saint, 1999).

So, the tool will provide greater access to majority of the populace. It will act as a means of introducing and re-orientating people to the new areas of research in the field of bioinformatics and biotechnology which can be very instrumental in boosting the agricultural products of African countries. 


\section{RESEARCH METHODS}

The research methods employed in this research work include the following two:

$>$ Design of the bioinformatics online distance educative tool.

$>$ Implementation of the bioinformatics online distance educative tool

Design and Implementation were done using the Borland Delphi 7 Enterprise edition within its Integrated Development Environment.

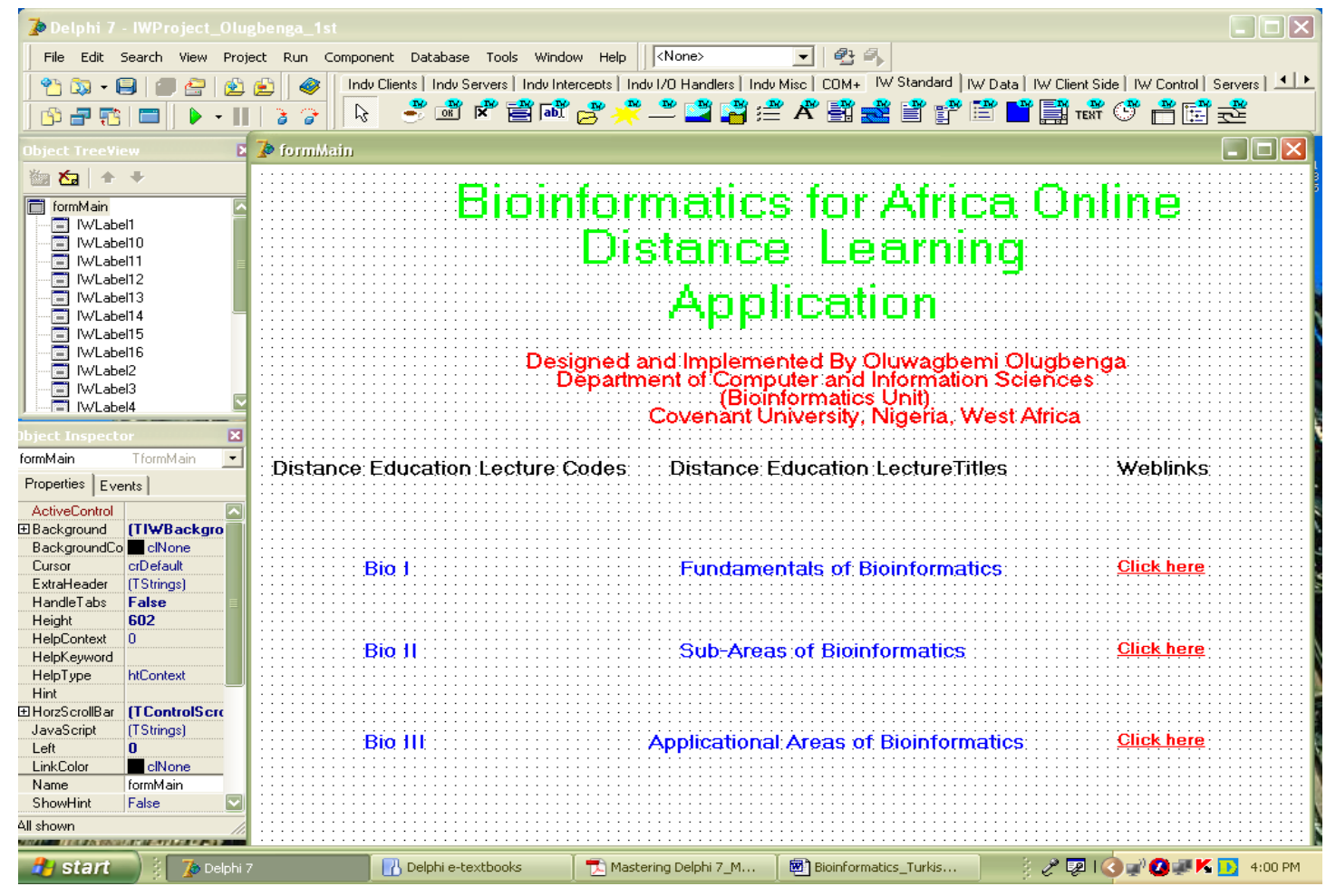

Figure: 1

Design phase using Borland Delphi 7

Some of the Borland Delphi 7 programming codes for the implementation is shown below: program IWProject_Olugbenga_1st;

\{PUBDIST\}

uses

IWInitStandAlone,

ServerController in 'ServerController.pas' \{IWServerController: TDataModule\}, Olugbenga_1st in 'Olugbenga_1st.pas' \{formMain: TIWForm1\}, DatamoduleUnit in 'DatamoduleUnit.pas' \{DataModule1: TDataModule\};

$\{\$ \mathbf{R} *$.res $\}$

begin

IWRun(TFormMain, TIWServerController); end. 
unit Olugbenga_1st;

\{PUBDIST\}

interface

uses

IWAppForm, IWApplication, IWTypes, Classes, Controls, IWControl, IWCompLabel, IWHTMLControls;

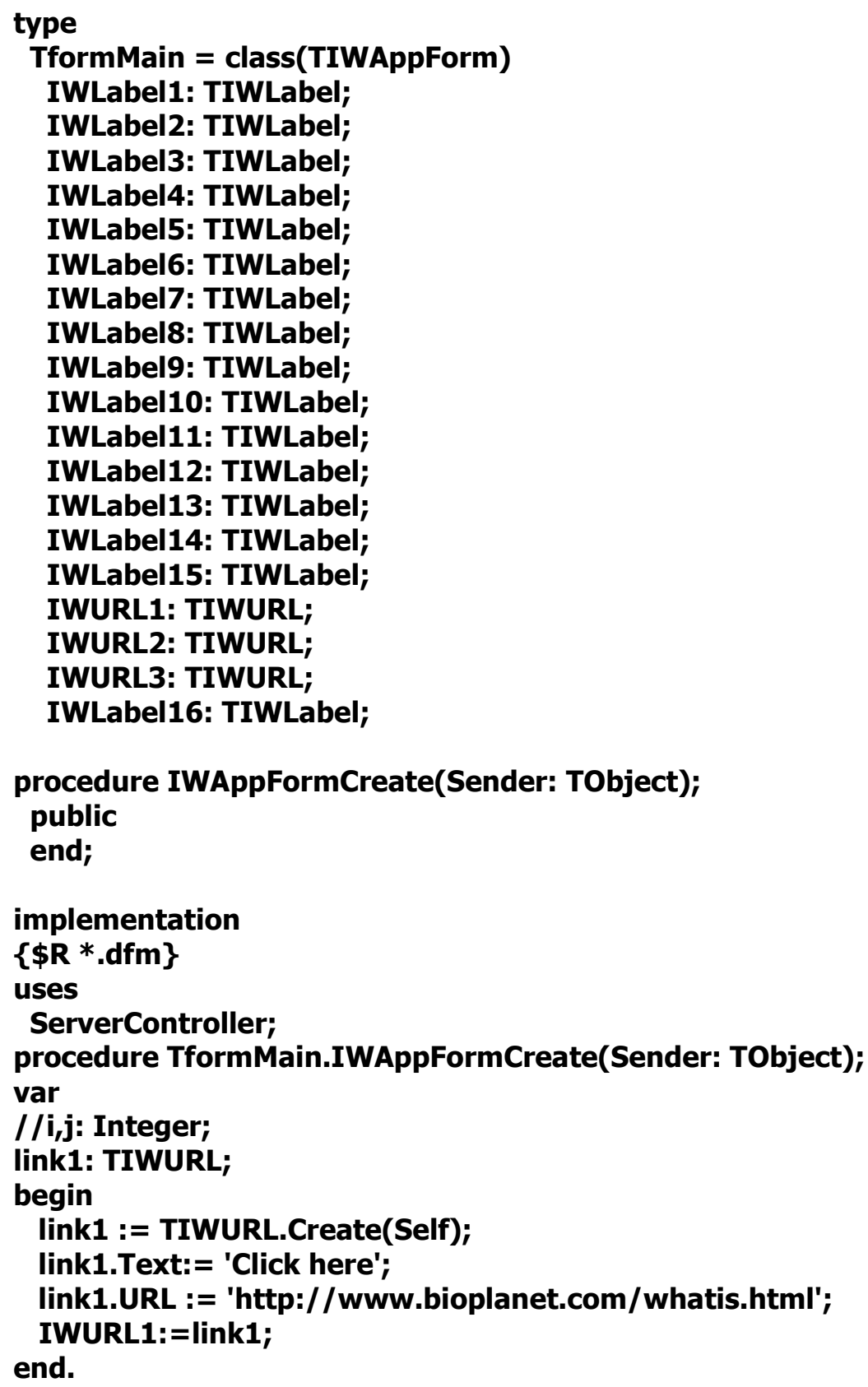




\section{RESULTS AND DISCUSSION}

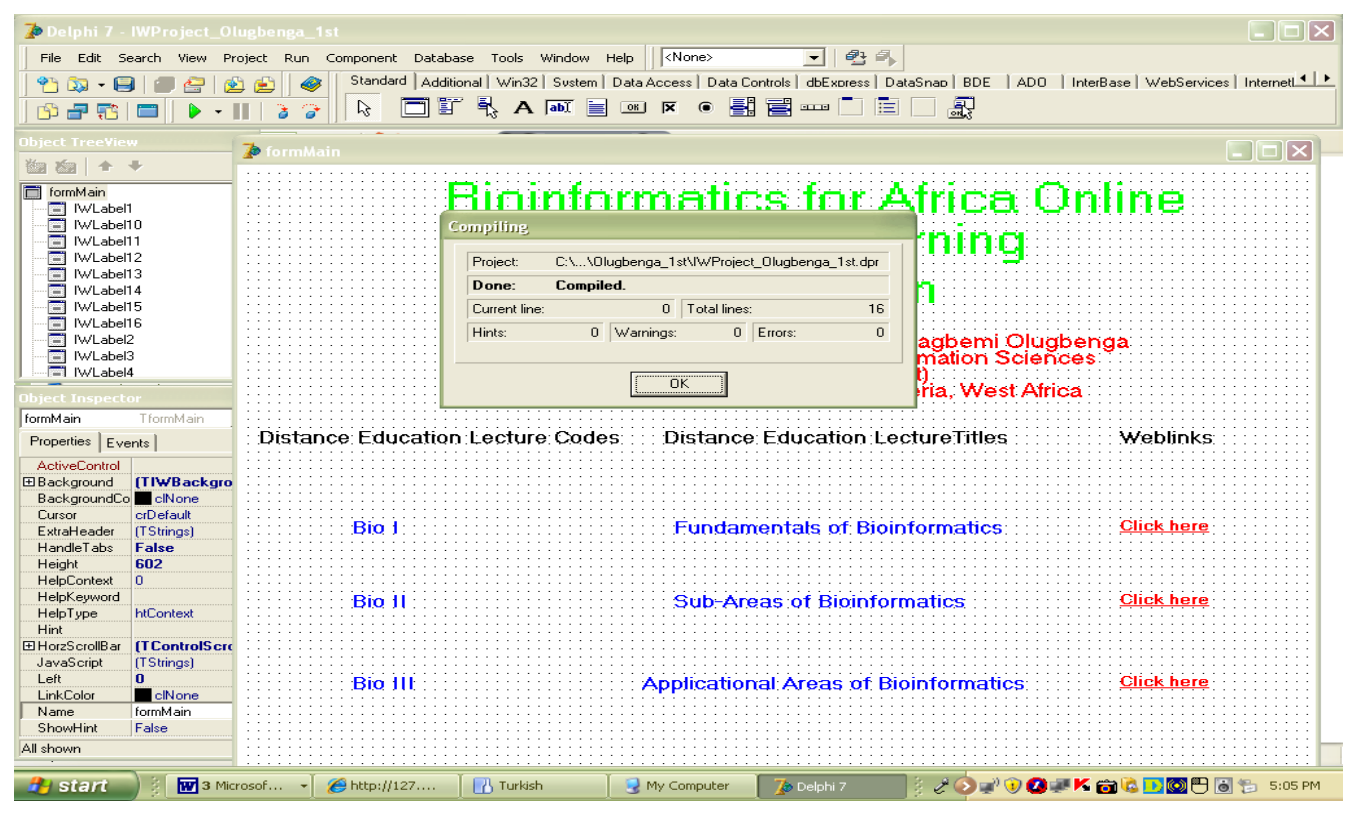

Figure: 2

Results during the compilation phase

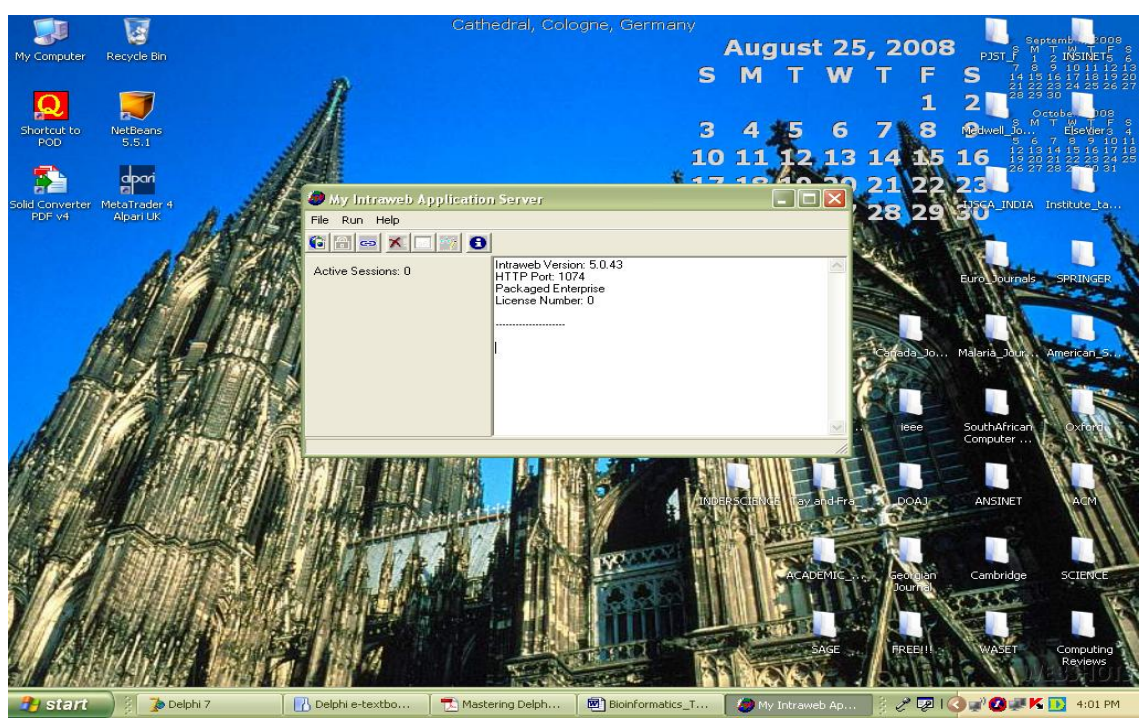

Figure: 3

Preliminary results during the running phase 


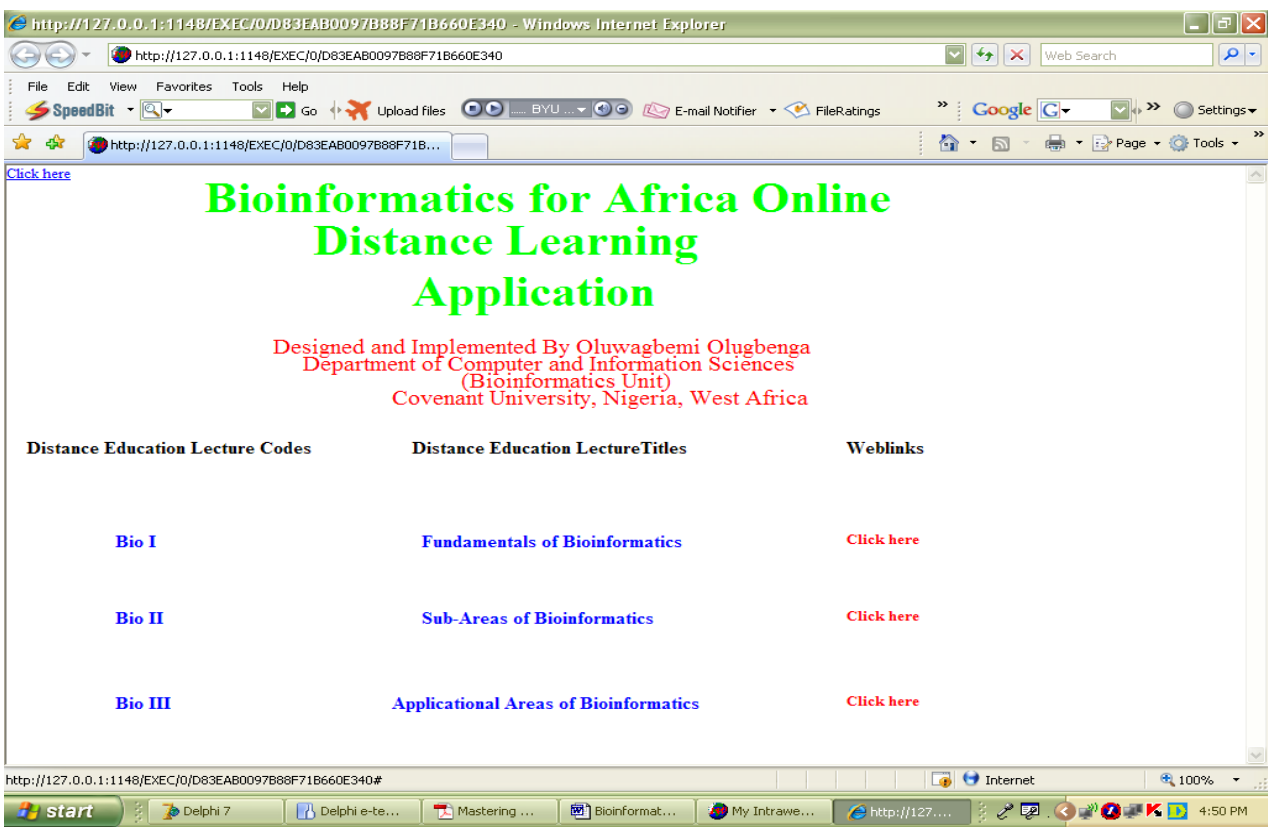

Figure: 4

Generation of the web application

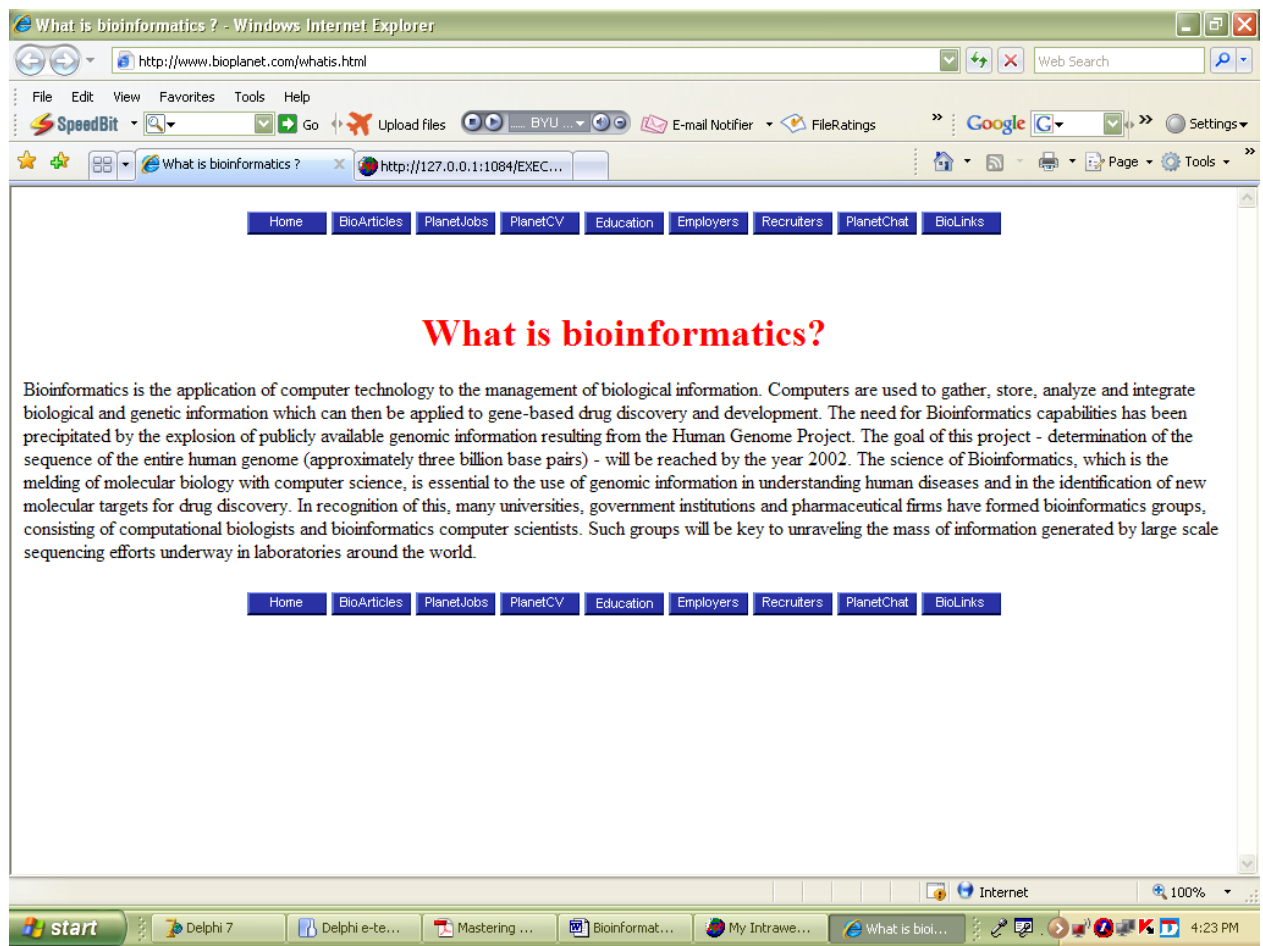

Figure: 5

Part of the fundamental aspect of the learning process 


\section{CONCLUSION}

In conclusion, in our fast changing world, web-based distance learning is becoming progressively more popular. Online distance education is one of the technologically enhanced ways to teach and train people who choose not to breach their professional, family and personal responsibilities through attendance of traditional, face-to-face classes.

The development and use of a bioinformatics distance education software, as a teaching tool, in some African countries holds great promise for accommodating the needs of the populace who live in cities, small towns and remote areas. The advent of the Internet will provide the opportunity to reach remote and inaccessible locations. The more educated and skilled professionals we produce, the faster we can develop our economy.

\section{BIODATA and CONTACT ADDRESSES of AUTHOR}

Oluwagbemi Olugbenga OLUSEUN was born in Ibadan, Nigeria, West Africa. He received the B.Sc degree in Computer Science from the University of Ilorin, Ilorin, Nigeria in 1999, and proceeded to receive the M.Sc degree in Computer Science from the Premier University of Ibadan, Ibadan, Nigeria, in 2004. He is currently a Ph.D Computer Science (Bioinformatics Option) student at the Department of Computer and Information Sciences, College of Science and Technology, Covenant University, Ogun State, Nigeria. He has also been lecturing in this University since 2006. He is also a member of the AAAS (American Association of Advancement of Science, NCS (Nigerian Computer Society) and ISCB (International Society for Computational Biology). His research interests are in the areas of bioinformatics, malaria research (using computational tools and bioinformatics approach), object-oriented and highlevel programming, simulation and modeling, artificial intelligence (neural networks), and software engineering.

Oluwagbemi Olugbenga OLUSEUN

Department of Computer and Information Sciences

College of Science and Technology

Covenant University

\section{REFERENCES}

Achuthsankar S Nair. (2007). Computational Biology \& Bioinformatics - A gentle Overview, Communications of Computer Society of India, January 2007

A DFID practice paper, Open and distance learning, Briefing June 2008.

Aluru, Srinivas, ed. Handbook of Computational Molecular Biology. Chapman \& Hall/Crc, 2006. ISBN 1584884061 (Chapman \& Hall/Crc Computer and Information Science Series).

Baldi, P and Brunak, S, Bioinformatics: The Machine Learning Approach, 2nd edition. MIT Press, 2001. ISBN 0-262-02506-X 
H. Fuks. "The Development and application of Distance Learning Courses on the Internet, " Open Learning, 17(2002):23-38

J. Wilson. "The power of distance learning guest editorial," Education 122, no.4 (2002): 638

Lim Yun Ping (2003) "A Global Experiment in Bioinformatics Distance Education,", S Star course Coordinator, Department of Biological Sciences, National University of Singapore,

Thomas Lengauer, (2000), Bioinformatics: From the Pre-genomic to the Postgenomic Era, ERCIM(European Research Consortium for Informatics and Mathematics) News No. 43, October 2000, http://www.ercim.org

William Saint, (1999), Tertiary Distance Education and Technology in Sub-Saharan Africa, Working Group on Higher Education Association for the Development of Education in Africa, THE WORLD BANK Washington, D.C.

Y. J. Katz. "Attitudes Affecting College Students' Preferences for Distance Learning," Journal of computer Assisted Learning, (2002). 18: 2-9. 